\title{
The Impact of a Surprise Donation Ask
}

\author{
Christine L. Exley and Ragan Petrie*
}

December 18, 2017

\begin{abstract}
Individuals frequently exploit "flexibility" built into decision environments to give less. They use uncertainty to justify options benefiting themselves over others, they avoid information that may encourage them to give, and they avoid the ask itself. In this paper, we examine whether a reluctance to give may arise even when such explicit flexibility is absent. We investigate whether merely alerting individuals to an upcoming prosocial ask - that is neither avoided nor occurs in an environment with flexibility - results in reduced prosocial behavior. That is, we investigate whether individuals use time to quickly find ways to decline prosocial asks and thus whether surprising individuals with prosocial asks increases compliance. Results from a field study and complementary online studies provide a clear answer: yes.
\end{abstract}

Keywords: charitable giving, prosocial behavior, self-serving biases, excuses

JEL codes: D64, C93

\section{Introduction}

One need not look far to see evidence of charitable acts. Volunteerism and giving in local communities are common. Social media campaigns, such as \#GivingTuesday, highlight giving opportunities online. Giving USA recently reported the highest level of (inflationadjusted) charitable giving in their 60-year history: $\$ 358.38$ billion in 2014 . Over $70 \%$ of this giving comes from individuals, as opposed to foundations, bequests, or corporations. While about one-third of donations benefit religious organizations, other popular causes range from education to the environment and animals (Giving USA Foundation, 2015).

\footnotetext{
*Exley: clexley@hbs.edu, Harvard Business School; Petrie: rpetrie@tamu.edu, Department of Economics, Texas A\&M University; We gratefully acknowledge funding for this project from George Mason University, Harvard Business School, Stanford University and Texas A\&M University. An early version of this paper was entitled "Finding Excuses to Decline the Ask."
} 
Despite this prevalence of giving, or perhaps in part because of it, there is a clear reluctance to give. Individuals walk in a direction away from solicitors (Andreoni, Rao and Trachtman, 2016; Trachtman et al., 2015), do not answer their door for fundraisers (DellaVigna, List and Malmendier, 2012), opt-out of future mail campaign solicitations (Kamdar et al., 2015), and avoid tasks that earn them money if a donation request is known to follow (Lin, Schaumberg and Reich, 2016). ${ }^{1}$ Individuals engage in motivated information avoidance to maintain "wiggle room" that justifies more selfish outcomes (Dana, Weber and Kuang, 2007; Bartling, Engl and Weber, 2014; Grossman, 2014; van der Weele, 2014; Grossman and van der Weele, 2016; Golman, Hagmann and Loewenstein, 2017). Individuals achieve outcomes that benefit themselves over others more often by engaging in self-serving evaluations of fairness (Babcock et al., 1995; Konow, 2000), ambiguity (Haisley and Weber, 2010), risk (Exley, 2015), beliefs about others (Di Tella et al., 2015; Klinowski, 2015; Gneezy et al., 2016), performance metrics (Exley, 2016), and competing moral principles (Danilov and Saccardo, 2016; Garbarino, Slonim and Villeval, 2016). ${ }^{2}$

Gino, Norton and Weber (2016) classify such behavior by noting that "when the context provides sufficient flexibility to allow plausible justification that one can both act egoistically while remaining moral, individuals seize on such opportunities to prioritize self-interest at the expense of morality." Earlier work highlights this precondition of flexibility to engage in less desirable or questionable behavior when they refer to mechanisms such as "elastic justification" (Hsee, 1995, 1996), "causistry" (Norton, Vandello and Darley, 2004), or "moral wiggle room" (Dana, Weber and Kuang, 2007). ${ }^{3}$ That is, prior literature suggests that a reluctance to give arises when that reluctance can be camouflaged to some extent via the flexibility embedded in the environment.

In this paper, we investigate whether individuals develop a reluctance to give even if the environment does not provide such flexibility. We examine individuals' responses to

\footnotetext{
${ }^{1}$ Avoidance may also reflect a desire to avoid empathetic triggers (Andreoni, Rao and Trachtman, 2016) or social pressure (DellaVigna, List and Malmendier, 2012), as also supported by additional work (Meer, 2011; Andreoni and Rao, 2011; Castillo, Petrie and Wardell, 2014, 2017). Relatedly, individuals desire to avoid others knowing about giving opportunities (Dana, Cain and Dawes, 2006; Broberg, Ellingsen and Johannesson, 2007; Lazear, Malmendier and Weber, 2012).

${ }^{2}$ Other factors that may be viewed self-servingly may relate to the reliance on chance or others' decisions (Dana, Weber and Kuang, 2007; Andreoni and Bernheim, 2009; Linardi and McConnell, 2011; Falk and Szech, 2013), the use of donations (Fong and Oberholzer-Gee, 2011; Li et al., 2015; Gneezy, Keenan and Gneezy, 2014; Batista, Silverman and Yang, 2015), or performance metrics (Yörük, 2016; Brown, Meer and Williams, 2014; Gneezy, Keenan and Gneezy, 2014; Meer, 2014).

${ }^{3}$ Indeed, decades ago, Snyder et al. (1979) show that when individuals are choosing between two movie theaters, they only avoid choosing the same movie theater as a person with disabilities if the movies are different - not the same. More recent examples show how individuals use flexibility when delegating decisions to others (Hamman, Loewenstein and Weber, 2010; Coffman, 2011; Bartling and Fischbacher, 2012), weighing plausible counterfactuals (Shalvi et al., 2011), assessing their own ability (Schwardman and van der Weele, 2016), or avoiding "moral tests" (Miller and Monin, 2016).
} 
a prosocial ask in an environment absent the ability to avoid the ask, competing norms, fairness, ambiguity, risk, and other forms of flexibility. In particular, we examine whether a reluctance to give emerges from merely giving individuals time to think about an impending ask. The prosocial ask is thus either announced in advance and "expected" or a surprise and "unexpected." While our environment does not provide flexibility, individuals may use this time to feel less compelled to be prosocial, perhaps by developing their own justifications for or summoning the mental strength for declining the ask.

Most environments are not conducive to examining the impact of expecting the ask absent the flexibility to avoid it. Future donation asks are often avoided if they are expected. Imminent donations asks, such as when individuals receive fundraising mail or are approached by solicitors, are likely recognized as such and do not allow for unexpected asks. We therefore embed our field experiment in an online voting contest where the ask is imminent but not necessarily expected. Recruitment materials for the voting contest do not highlight that an ask will occur. Instead, they highlight that the animal group that receives the most votes will win a large monetary prize.

Upon arriving at the contest webpage, individuals learn that they must complete a threestep registration process for their vote to count. In the first step, individuals vote for their favorite animal group, and the upcoming ask is still not mentioned. ${ }^{4}$ In the second step, individuals provide information on how they know their voted-for animal group, and depending on their randomly assigned treatment group, may learn about the upcoming ask. In the third step, individuals face the ask and decide whether to click-through to the donation page of their voted-for animal group. Strong treatment effects and attrition of only $1 \%$ validate this design choice. The use of an online voting contest also maintains the benefits of a natural environment where individuals are not directly informed of, and likely remain unaware of, the on-going research. ${ }^{5}$ The six treatments groups - which influence what participants view during the second step before the ask - arise from two conditions.

Our first condition addresses our central question by varying the expectation of the ask. When the ask is expected, the second step mentions the upcoming donation ask by saying "Do you love [group name]? Register your vote in the next step, and if you want to, donate to them!" When the ask is unexpected, the second step instead reads "Do you love [group name]? Register your vote in the next step!"

Our second condition investigates potential policy interventions that may counter a re-

\footnotetext{
${ }^{4}$ While individuals are thus unlikely to expect the ask at this point, it is also worth noting that the degree to which individuals already expect the ask biases against our treatment effects that arise from the manipulation of the expectation of the ask.

${ }^{5}$ Most individuals have voted in an online contest or poll before (Google Consumer survey, Oct. 2015, $\mathrm{n}=500$ ) and over a quarter have done so to help others (Google Consumer survey, Oct. 2015, n=500).
} 
luctance to give. ${ }^{6}$ We compare the effectiveness of providing no information, unavoidable information and avoidable information on "why to give" in the second step. In line with industry practice, provided information features an adoption story about a rescued dog.

Our contest yielded approximately six-thousand participants. When no information is provided, we find that the mere expectation of the ask causes click-through rates to charity websites to fall by $22 \%$ from 0.51 to 0.40 . Individuals appear readily able to avoid clickingthrough when given time - in practice, just a few seconds - to think about it. A reluctance to give extends beyond settings with explicitly provided flexibility and hints that being caught on the spot or surprised with a request can increase compliance.

The paper proceeds as follows. Section 2 presents design, Section 3 discusses the collected data, Section 4 details our results, Section 5 examines whether our results extend to a different context that allows us to also capture donation data, and Section 6 concludes.

\section{Design}

\section{Step 1 - Vote for favorite group}

For the first step (see Figure 1), an individual votes for her favorite animal group and pro-vides her first name, last name, email address and zip Figure 1: Screen shot of first step of the voting contest code. She also confirms her eligibility by agreeing to the terms-of-use and stating that she is 18 years or older, resides in the US and will only vote once. An individual only views information that this contest is related to a research study if she chooses to click on the terms-of-use hyperlink, and in the $4 \%$ of

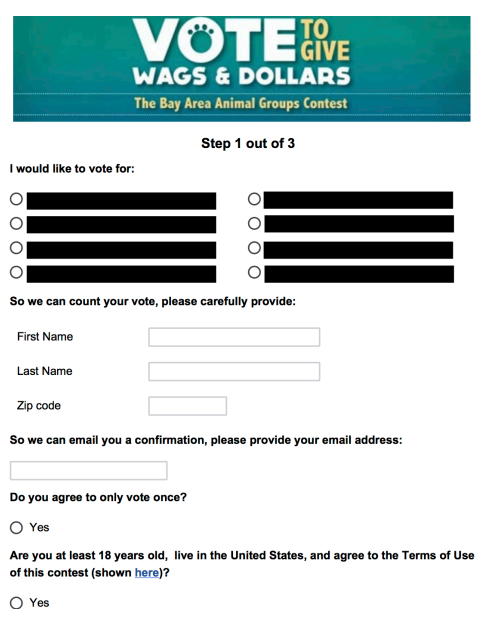
cases where this occurs, note that this hyperlink click precedes the treatment variations shown in the second step.

Step 2 - Presented with any materials related to treatment group

In the second step, the top portion of the page requests information on how the individual knows her voted-for group - e.g. whether she has adopted from them, attended one of their events, donated money to them, used their services, volunteered for them, worked as

\footnotetext{
${ }^{6}$ This particular investigation was also instrumental to recruiting our non-profit partners.
} 
a staff member, never interacted with them, and/or interacted in some other way. The bottom portion of the page displays any information related to the treatment group. The six treatments vary on two dimensions: whether the upcoming ask is mentioned or not, and whether information on why to give is not provided, is unavoidable, or is avoidable. Figure 2 displays the first two "No Information" treatments, which only vary by whether the short message at the bottom of the page.

No Information-Unexpected Ask: "Do you love [group name]? Register your vote in the next step!"

No Information-Expected Ask: "Do you love [group name]? Register your vote in the next step, and if you want to, donate to them!"

Figure 2: No Information treatments

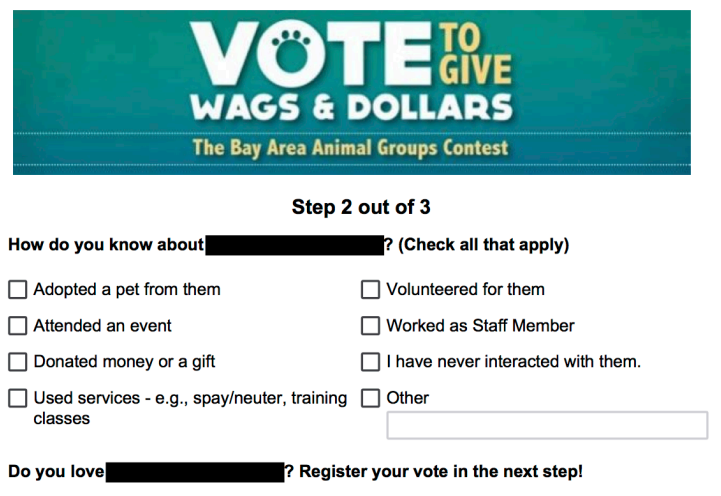

(a) Unexpected Ask

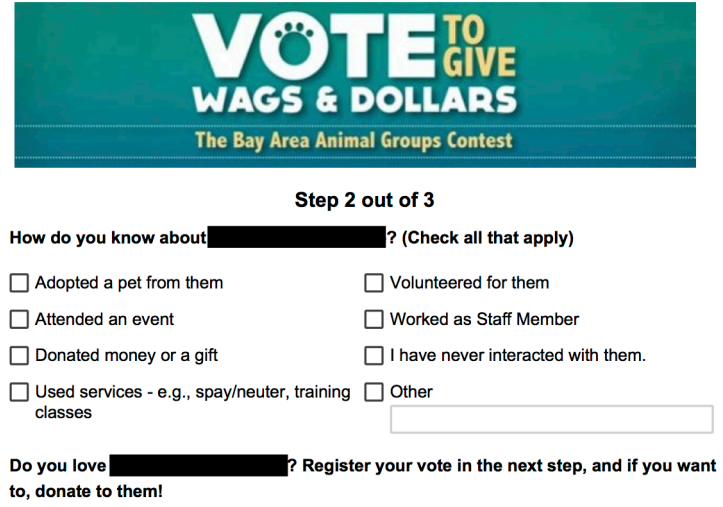

(b) Expected Ask

Figure 3 displays the two "Unavoidable Information" treatments, which add in information on why an individual might want to donate to her voted-for animal group. This information involves 140-170 words detailing a real adoption story of a dog rescued by her voted-for group. Even if participants do not fully read the information, the inclusion of one large photograph or two small photographs helps to convey the message. The adoption story follows the message that varies the expectation of the ask.

Unavoidable Information-Unexpected Ask: "Do you love [group name]? Read '[dog name]'s Story' below about a pup they saved, and register your vote in the next step!"

Unavoidable Information-Expected Ask: "Do you love [group name]? Read '[dog name]'s Story' below about a pup they saved, register your vote in the next step, and if you want to, donate to them!" 
Figure 3: Unavoidable Information treatments
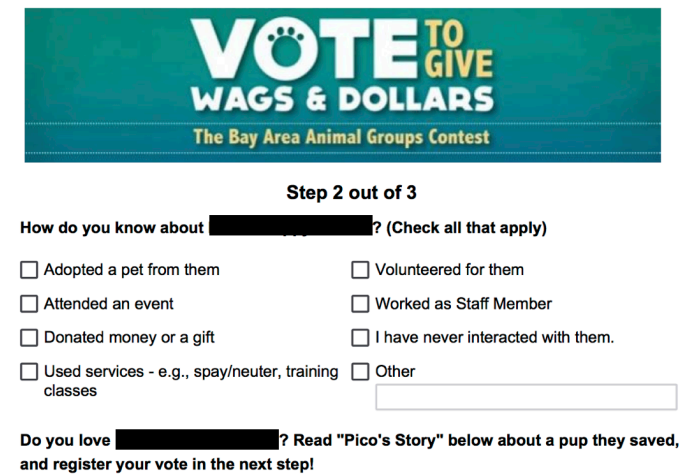

and register your vote in the next step!

Pico's Story

Pico was picked up by after someone reported seeing him kicked in the face. He was a teeny tiny thing, weighing in just under $1 \mathrm{lb}$, with open wounds covering his sweet face.

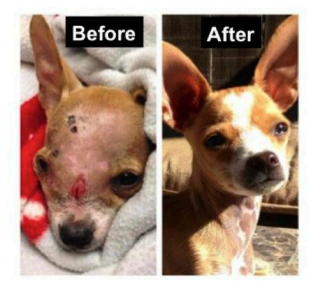

up before he got to the shelter, and un be vet assured us his injures were purely cosmetic.

With good food, LOVE and attention he healed up completely and thrived in his foster home with two little girls and a couple of cats

This goofy and playful survivor, who captures the hearts of everyone he meets, was adopted by an amazing family. He is now living the life he deserves: in a family that will love him forever!
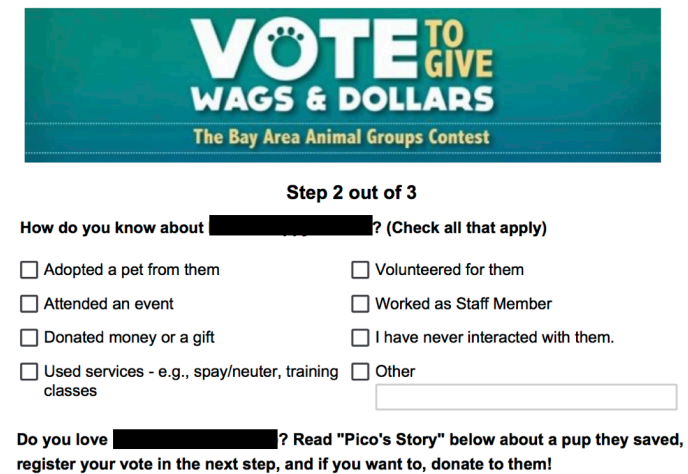

register your vote in the next step, and if you want to, donate to them

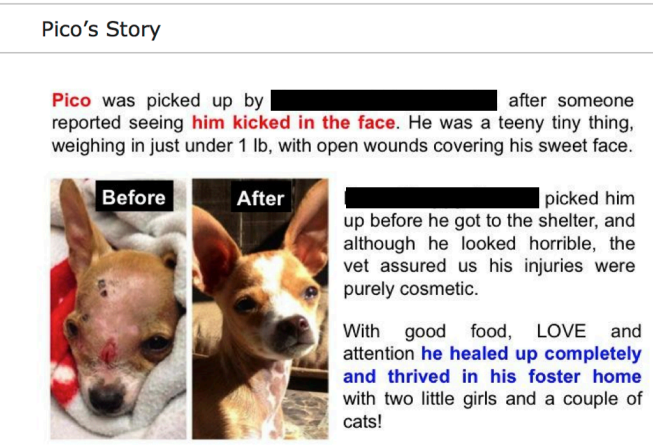

This goofy and playful survivor, who captures the hearts of everyone he meets, was adopted by an amazing family. He is now living the life he deserves: in a family that will love him forever!

(a) Unexpected Ask

(b) Expected Ask

Figure 4 displays the final two "Avoidable Information" treatments. An individual can click the bar at the bottom of the page to reveal the information or not click to avoid the information. This bar follows the message that varies the expectation of the ask.

Avoidable Information-Unexpected Ask: "Do you love [group name]? Click to read '[dog name]'s Story' below about a pup they saved, and register your vote in the next step!"

Avoidable Information-Expected Ask: "Do you love [group name]? Click to read '[dog name]'s Story' below about a pup they saved, register your vote in the next step, and if you want to, donate to them!" 
Figure 4: Avoidable Information treatments

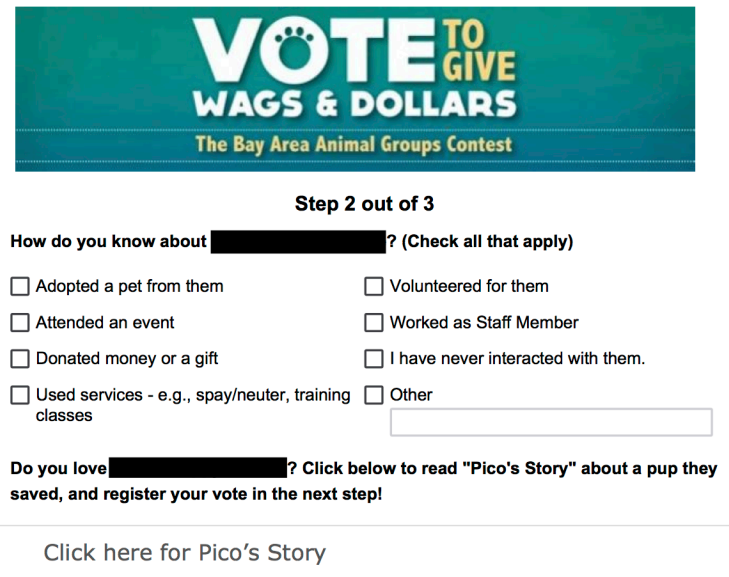

(a) Unexpected Ask
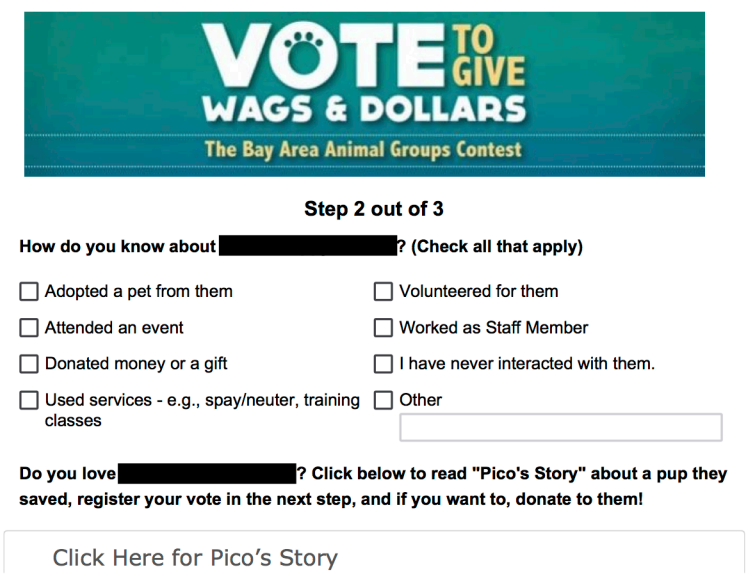

(b) Expected Ask

\section{Step 3 - Choose whether to click-through to donation page}

As shown in Figure 5, during the third and final step, an individual must decide whether to click-through to her voted-for group's donation page. To ensure an individual makes an active decision about clickingthrough, notice that she must Figure 5: Screen shots of third step of the voting contest indicate this decision before clicking on the "register my vote" button. After clicking this button, a screen appears confirming the vote has been registered and a confirmation email is sent. If the voter chooses to click-through to the donation page of her voted-for animal group, she is automatically redirected to

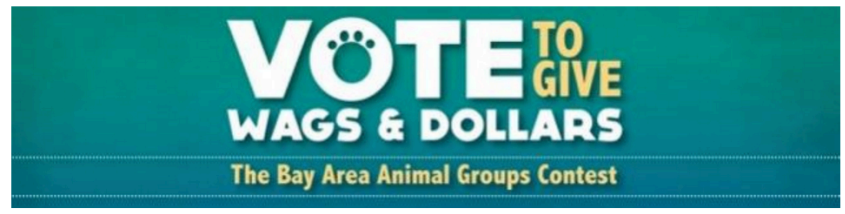

Step 3 out of 3

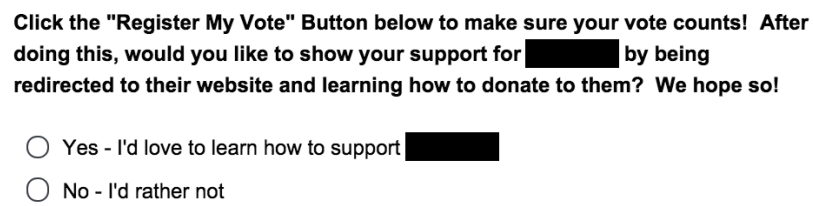

Register My Vote that page. 


\section{Data}

\subsection{Participant Recruitment}

From March 9th to 22nd of 2015, individuals could vote for one out of eight participating Bay Area animal groups. ${ }^{7}$ To encourage participation, the group with the most votes by the end of the contest won $\$ 4,000$. Additionally, one voter was chosen at random, and the group that individual voted for won $\$ 1,500$. This smaller prize provided an incentive for all individuals to register a vote, even if their voted-for group was unlikely to win the $\$ 4,000$.

The contest was hosted via a Qualtrics survey on the website of an organization that helps individuals find dogs for adoption (www.wagaroo.com) from animal shelters, rescue groups, or families needing to rehome their dogs. The hosting organization did not participate in the contest. ${ }^{8}$ Groups participating in this contest, however, had interacted with the hosting organization before, mostly by posting profiles of their dogs available for adoption on the hosting organization's website. This relationship helped to ensure supporters of the participating groups about the legitimacy of the contest. The left panel of Figure 6 shows how the landing page for the contest appeared.

To facilitate voter recruitment, participating groups were provided with professionally designed promotional materials. The right panel of Figure 6 shows an example. Groups were free to use these materials and any of their own materials to promote the contest via outlets such as Facebook, Twitter, their own web page, and email lists. ${ }^{9}$

Figure 6: Voting Contest

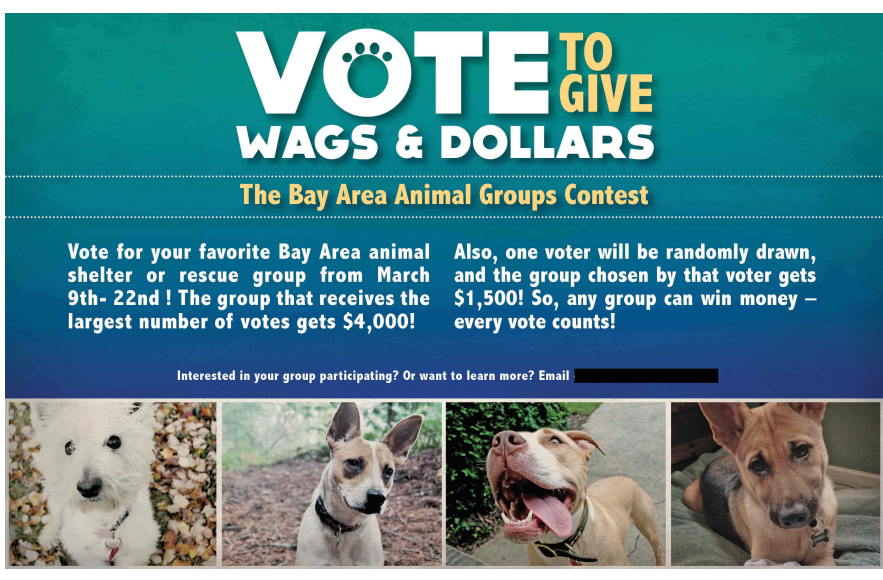

(a) Landing Page

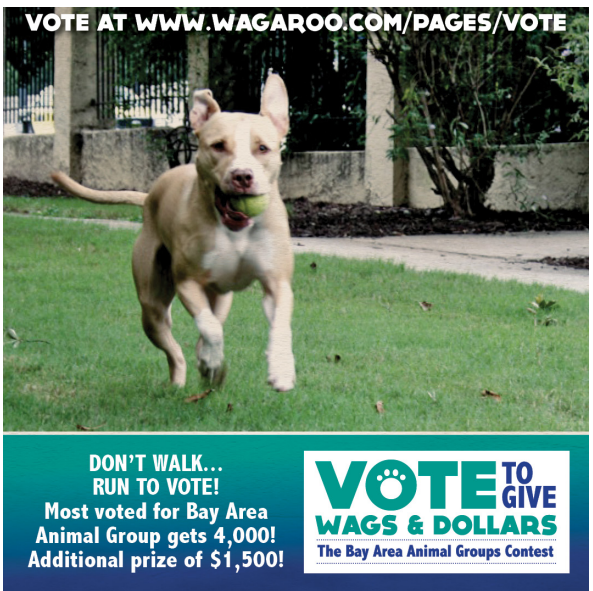

(b) Example Promotional Ad

\footnotetext{
${ }^{7}$ Random assignment to treatment groups was balanced across the 2 weeks of the contest, and our results are robust to only considering data from the first or second week.

${ }^{8}$ One of this study's authors is a co-founder of the organization.

${ }^{9}$ Our own monitoring suggests that most promotion took place on Facebook.
} 


\subsection{Participant Completion}

Out of the 6,664 individuals who began the three-step voting registration process, only $4 \%$ did not complete all three steps. Excluding individuals with a duplicate name and/or email address reduces the rate of attrition to only $1 \%$ of the remaining 6,059 individuals who began the registration process. ${ }^{10}$ The attrition rate remains constant across all treatment groups, and our results are not sensitive to excluding individuals on the basis of duplicate names and/or email addresses. ${ }^{11}$ The analysis that follows therefore excludes all potential duplicates and focuses on the 5,976 unique and successfully cast votes, thus yielding 980 1,005 in each treatment group.

\subsection{Description of the Data}

For the 5,976 participants, we measured the amount of time participants spent on each step. While the median time spent on the first step ( 45 seconds) and last step (11 seconds) did not vary across treatments, the amount of time spent on the second step varied in the direction one would expect. In looking across the unexpected and expected ask treatments, the median time was 19-21 seconds when no information was provided, 26-27 seconds when the information was avoidable, and 31-32 seconds when the information was unavoidable.

Our data also consist of information directly inputted as part of the three-step voting registration. From participants' inputted names in the first step, computer code that predicts gender indicates $83 \%$ of participants were female, $14 \%$ were male, and $4 \%$ were not known. From participants' answers about how they knew their voted-for group in the second step, $26 \%$ have adopted a pet from them, $22 \%$ have donated money or a gift, $17 \%$ have attended an event, $15 \%$ have volunteered, $10 \%$ have used a service such as spay/neuter or training classes, and $1 \%$ have worked as a staff member. Appendix Table A.1 shows that the frequency of these interactions, as well as predicted gender, are not different across the treatment groups.

Participants' active decisions about whether to click-through to the donation page of their voted-for animal group in the third step is our central outcome metric. Among voters who chose to click-through, subsequent donation decisions were only observed by the involved animal group. Data collection from the animal groups unfortunately resulted in noisy and non-standardized information. Even if we consider this data, the observed donation level of $1-2 \%$ leaves us underpowered to detect any significant differences across our treatment groups. ${ }^{12}$ Analysis of donation data, however, is possible with our complementary online

\footnotetext{
${ }^{10}$ The reduced attrition rate may reflect some individuals starting to register a second vote but then quitting when they remembered the one-vote-per-person rule. In general, the attrition rate is low in our study, and this reflects the strong incentive to complete all three steps in order to register one's vote.

${ }^{11}$ This is important as it is possible that some individuals shared the same name as another participant, or that more than one individual shared a particular email address, such as a family email address.

${ }^{12}$ Although noisy, it is interesting to note that typically around $2 \%$ of individuals choose to give, conditional
} 
experiments (see Section 5).

Before turning to how click-through rates change in response to our treatment variations in the next section, it is useful to note that click-through rates, or targeted website traffic to donation pages, are highly valued metrics. For instance, in their survey paper on political campaigns, Nickerson and Rogers (2014) discuss how "data collected from online activities can be of particular value" as the barrier to entry is low and it facilitates predictions about levels of support and likelihood of subsequent actions. Given the increasing professionalism of the nonprofit sector (Hwang and Powell, 2009), it may therefore be no surprise that a similar focus appears to be developing among nonprofit organizations. Out of the 84 nonprofit organizations (netting over $\$ 400$ million dollars) featured in the $2015 \mathrm{M}+\mathrm{R}$ Benchmarks Study, $76 \%$ paid for web marketing. ${ }^{13}$ The belief that this investment may be worthwhile is also supported by $\mathrm{M}+\mathrm{R}$ Benchmarks Study reporting an average of $\$ 610$ dollars in donations for every 1,000 website visitors compared to only an average of $\$ 40$ for every 1,000 fundraising emails sent.

As a baseline, it is therefore encouraging to note that $46 \%$ of participants in our study choose to click-through to the donation page of their voted-for animal group. This average compares favorably to available benchmarks about how often individuals click-through in response to emails. ${ }^{14}$

\section{$4 \quad$ Results}

\subsection{Treatment Effects on Click-through Rates}

In the No Information - Unexpected Ask treatment, voters are reminded to register their vote in the next step. The addition of 8 words that alert voters to the upcoming donation ask in the No Information - Expected Ask treatment has a substantial impact. Figure 7 shows that the mere expectation of the ask causes click-through rates to significantly decrease by $22 \%$ from 0.51 to only 0.40 . Columns (1) and (2) of Table 1 confirm the significance of this drop via a linear probability model of the likelihood to click-through on expecting the ask, both when controls are not included and when controls are included for each voter's gender, day during contest that they voted, selected animal group, and ways in which they

on being asked in a mail campaign (Huck and Rasul, 2011; Karlan and List, 2007; Karlan and Shafir, 2011; Eckel and Grossman, 2008) and via social media (Castillo, Petrie and Wardell, 2014, 2017).

${ }^{13}$ For details, please see http://mrbenchmarks.com.

${ }^{14}$ The $\mathrm{M}+\mathrm{R}$ Benchmark Study reports a click-through of $0.48 \%$ from fundraising emails, with only $14 \%$ even being opened. MailChimp reports a click-through of $2.89 \%$ from large email campaigns initiated by nonprofit organizations, with only $25.45 \%$ even being opened (see http://mailchimp.com/resources/research/ email-marketing-benchmarks). Silverpop reports that even the top-quartile of nonprofit organizations only have a click-through of $4.8 \%$, with only $27.3 \%$ even being opened (see http://www.silverpop.com/Documents/ Whitepapers/2013/WP_EmailMarketingMetricsBenchmarkStudy2013.pdf). We are not aware of any benchmark of clickthrough rates from an online contest. 
know their selected animal group. ${ }^{15}$ That is, even without the ability to avoid the ask and without the provision of information or factors that facilitate self-serving evaluations, individuals appear readily able to find ways to decline the ask when it is expected. They may use the time to develop their own justifications about why they should decline the ask. Such justifications may involve convincing themselves that there are better prosocial alternatives to this opportunity, reasoning that they do not have time to give now, forming beliefs that allow them to think of themselves as prosocial even when declining this ask perhaps by reflecting on prior prosocial behavior or intended future prosocial behavior, etc. They may also use the time to overcome mental barriers to declining the ask or summoning the psychological strength needed to decline the ask.

Turning next to the policy-related results, we investigate whether expecting the ask is less detrimental when declining it may be more difficult or less desirable. Consistent with this possibility, there is no longer a negative impact of expecting the ask when unavoidable information on why to give is provided: click-through rates remain at 0.47 regardless of whether the ask is expected or unexpected. Columns (3) and (4) of Table 1 show providing unavoidable information significantly and indeed fully counteracts the negative impact of expecting the ask. ${ }^{16}$ In addition to validating the common practice of charities bundling donation requests with unavoidable information on why to give, these results are consistent with it being more difficult to find ways to decline the ask when presented with unavoidable information on why to give. ${ }^{17}$

When information is instead avoidable, the negative impact of expecting the ask persists. In the Avoidable Information treatments, expecting the ask causes a significant $15 \%$ decrease from a click-through rate of 0.48 to 0.41 . Columns (5) and (6) of Table 1 further confirm that providing avoidable information does not significantly counter the negative impact of expecting the ask. ${ }^{18}$

A limitation to providing information on why to give arises when individuals can avoid the

\footnotetext{
${ }^{15}$ All results in this paper are robust to considering Probit regression results as opposed to regression results from a linear probability model.

${ }^{16}$ This is seen by us failing to reject that the sum of the coefficients on Expected Ask and Expected Ask* Unavoidable Information is different than 0 in Column (3) of Table $1(p=0.91)$.

${ }^{17}$ An alternative explanation could be that expecting the ask is no longer detrimental when unavoidable information is provided because the unavoidable information causes some participants not to notice the upcoming ask message. Participants may not expect the ask even when it is explicitly mentioned in the Unavoidable Information - Expected Ask treatment. Inconsistent with this alternative explanation, Appendix C shows that survey respondents are equally likely to "expect the ask" (i.e., indicate that they think an invitation to donate to the voted-for animal group is likely to occur in Step 3) after viewing Step 1 and Step 2 materials when evaluating the No Information - Expected Ask treatment as when evaluating the Unavoidable Information - Expected Ask treatment ( $77 \%$ versus 80\%, two-sided t-test $p=0.56$ ).

${ }^{18}$ This is seen by us rejecting that the sum of the coefficients on Expected Ask and Expected Ask*Avoidable Information is different than 0 in Column (5) of Table $1(p=0.01)$.
} 
Table 1: Click-through regressions

\begin{tabular}{|c|c|c|c|c|c|c|}
\hline \multirow{3}{*}{ Information: } & \multicolumn{6}{|c|}{ Linear probability model of click-through } \\
\hline & \multicolumn{2}{|c|}{ None } & \multicolumn{2}{|c|}{$\begin{array}{c}\text { None or } \\
\text { Unavoidable }\end{array}$} & \multicolumn{2}{|c|}{$\begin{array}{c}\text { None or } \\
\text { Avoidable }\end{array}$} \\
\hline & (1) & $(2)$ & $(3)$ & $(4)$ & $(5)$ & $(6)$ \\
\hline Expected Ask & $\begin{array}{c}-0.11^{* * *} \\
(0.03)\end{array}$ & $\begin{array}{c}-0.11^{* * *} \\
(0.03)\end{array}$ & $\begin{array}{c}-0.11^{* * *} \\
(0.03)\end{array}$ & $\begin{array}{c}-0.11^{* * *} \\
(0.03)\end{array}$ & $\begin{array}{c}-0.11^{* * *} \\
(0.03)\end{array}$ & $\begin{array}{c}-0.11^{* * *} \\
(0.03)\end{array}$ \\
\hline Unavoidable Info & & & $\begin{array}{l}-0.04 \\
(0.03)\end{array}$ & $\begin{array}{l}-0.04 \\
(0.03)\end{array}$ & & \\
\hline $\begin{array}{l}\text { Expected Ask } \\
\text { * Unavoidable Info }\end{array}$ & & & $\begin{array}{l}0.11^{* *} \\
(0.03)\end{array}$ & $\begin{array}{l}0.10^{* *} \\
(0.03)\end{array}$ & & \\
\hline Avoidable Info & & & & & $\begin{array}{l}-0.03 \\
(0.02)\end{array}$ & $\begin{array}{l}-0.03 \\
(0.02)\end{array}$ \\
\hline $\begin{array}{l}\text { Expected Ask } \\
\text { * Avoidable Info }\end{array}$ & & & & & $\begin{array}{c}0.04 \\
(0.03)\end{array}$ & $\begin{array}{c}0.03 \\
(0.03)\end{array}$ \\
\hline Previous Supporter & & $\begin{array}{l}0.04^{* *} \\
(0.02)\end{array}$ & & $\begin{array}{c}0.07^{* * *} \\
(0.02)\end{array}$ & & $\begin{array}{l}0.06^{* *} \\
(0.02)\end{array}$ \\
\hline Constant & $\begin{array}{l}0.51^{* * *} \\
(0.04)\end{array}$ & $\begin{array}{c}0.43^{* * *} \\
(0.03)\end{array}$ & $\begin{array}{l}0.51^{* * *} \\
(0.04)\end{array}$ & $\begin{array}{c}0.45^{* * *} \\
(0.04)\end{array}$ & $\begin{array}{l}0.51^{* * *} \\
(0.04)\end{array}$ & $\begin{array}{c}0.43^{* * *} \\
(0.02)\end{array}$ \\
\hline Controls & no & yes & no & yes & no & yes \\
\hline Observations & 1989 & 1989 & 3973 & 3973 & 3987 & 3987 \\
\hline Click-through rates & 0.46 & 0.46 & 0.46 & 0.46 & 0.45 & 0.45 \\
\hline
\end{tabular}

${ }^{*} p<0.10,{ }^{* *} p<0.05,{ }^{* * *} p<0.01$. Standard errors are clustered at the voted-for animal group level and shown in parentheses. The results are from a linear probability model of likelihood to click-through to the donation page of voted-for animal group. Expected Ask, Unavoidable Info, and Avoidable Info are indicators for when the ask is expected, the information provided is unavoidable, and the information provided is avoidable. Controls include indicators for each individual's day that they voted during the contest, selected animal groups, previous supporters, and males.

information. The fact that our information treatments fail to ever increase click-through rates above those of the No Information - Unexpected Ask treatment further suggests additional limitations. ${ }^{19}$ On one hand, it may be that the information in our study only influences the decisions of marginal individuals who are influenced by the expectation of the ask. On the other hand, it may be that providing information helps individuals to find ways to decline the ask. In the Unexpected Ask treatments and consistent with survey results

\footnotetext{
${ }^{19}$ The coefficient estimate on Unavoidable Info in Column (3) of Table 1 shows that the Unavoidable Information - Unexpected Ask treatment click-through rate is insignificantly lower than the No Information - Unexpected Ask treatment click-through rate. The coefficient estimate on Avoidable Info in Column (5) of Table 1 shows that the Avoidable Information - Unexpected Ask treatment click-through rate is insignificantly lower than the No Information - Unexpected Ask treatment click-through rate. If we instead collapsed the Unavoidable and Avoidable Information treatments, then the Information treatment click-through rate is also insignificantly lower than the No Information - Unexpected Ask treatment click-through rate $(p=0.13)$.
} 
shown in Appendix C, individuals may infer from the provision of the information that an ask is forthcoming even without it being explicitly mentioned. ${ }^{20}$ Moreover, when the ask is expected and consistent with evidence shown in Section 4.3, individuals may be able to distort the information in a self-serving manner to justify why they should decline the ask.

Figure 7: Clicks-through rates

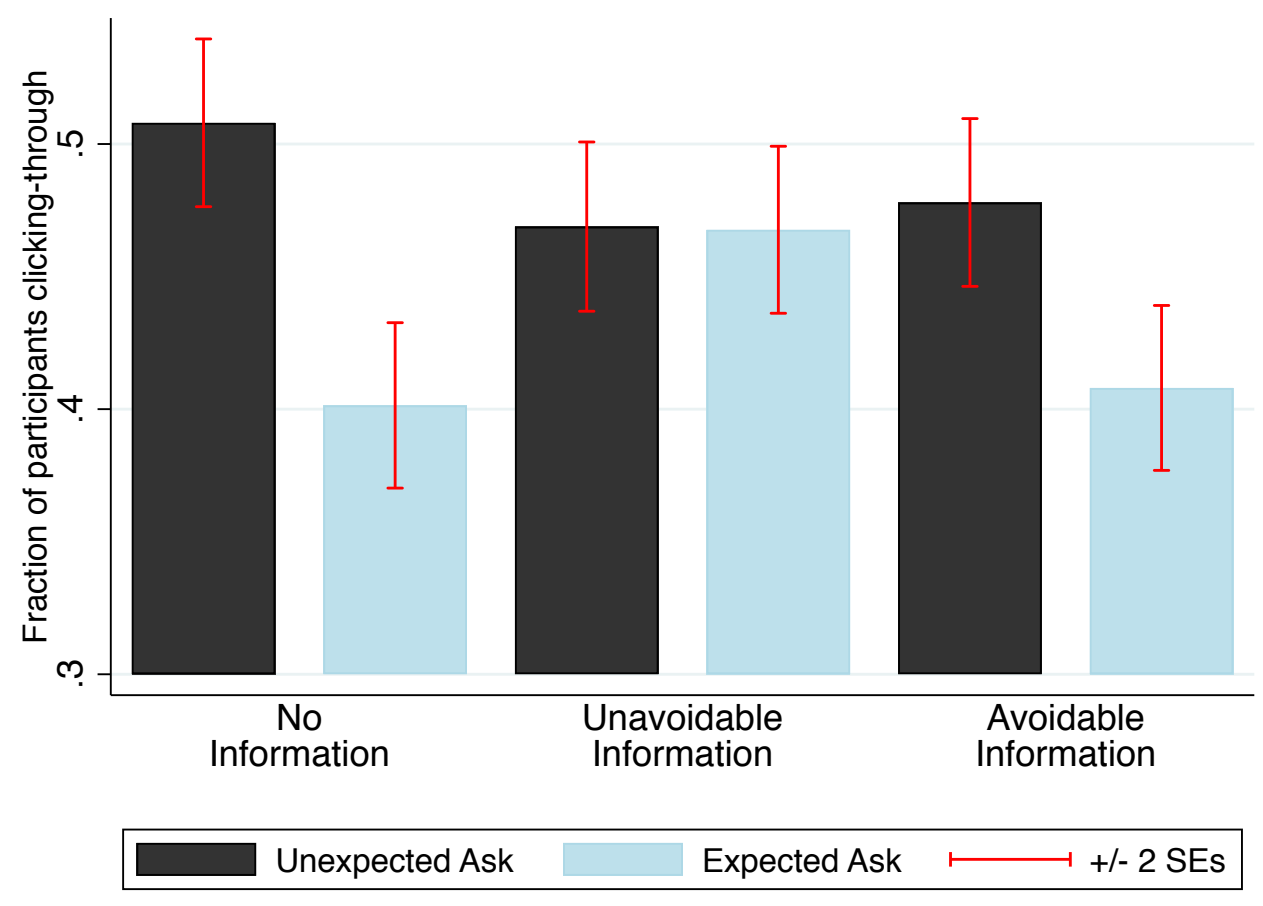

\subsection{Heterogeneous Treatment Effects on Click-through Rates}

Charities often consider how to target fundraising appeals towards new versus previous supporters, and prior literature confirms that responsiveness to various factors, such as image concerns or financial incentives, vary across these two groups. ${ }^{21}$ To consider the potential for heterogeneous effects by the level of prior support, we therefore turn to the gathered

\footnotetext{
${ }^{20}$ Consistent with this explanation, Appendix C shows that survey respondents are equally likely to "expect the ask" (i.e., indicate that they think an invitation to donate to the voted-for animal group is likely to occur in Step 3) after viewing Step 1 and Step 2 materials when evaluating the Unavoidable Information - Expected Ask treatment as when evaluating the Unavoidable Information - Unexpected Ask treatment (80\% versus $76 \%$, two-sided t-test $p=0.52$ ).

${ }^{21}$ For instance, heterogeneous findings by prior prosocial behavior appears in relation to responsiveness to natural disasters (Lilley and Slonim, 2016), financial incentives (Niesse-Ruenzi, Weber and Becker, 2014; Lacetera, Macis and Slonim, 2014), social image concerns (Exley, Forthcoming), and self-image concerns (Gneezy et al., 2012).
} 
information on how voters know their voted-for animal group. ${ }^{22}$ We classify $54 \%$ of voters as previous supporters if they have previously adopted from, donated to, volunteered for, attended an event of, used services of, or been a staff member for their voted-for animal group. The remaining $46 \%$ of new supporters include anyone who has not engaged in those forms of previous support; they have never interacted with their voted-for animal group or have only interacted in some other way. Other ways largely involve small interactions, and in particular, liking the group on Facebook.

Appendix Table A.2 displays the main click-through regression results when the treatment effects are interacted with an indicator for being a previous supporter. As shown by the coefficient on Expected Ask, expecting the ask causes click-through rates to significantly drop by $35 \%$ from 0.53 to 0.37 among new supporters. As shown by the coefficient on Expected Ask*Previous Supporter, this drop is qualitatively but not significantly smaller among previous supporters. The $14 \%$ decrease from 0.49 to 0.42 in click-through rates among previous supporters is indeed not statistically significant. ${ }^{23}$ In other words, while new supporters appear to capitalize on the opportunity to find ways to decline the ask when it is expected, a similar reluctance does not significantly emerge among previous supporters. ${ }^{24}$

These heterogeneous findings add to previous literature documenting how prior prosocial behavior is predictive of self-serving responses. In particular, Karlan and Wood (2017) find more adverse responses to effectiveness information among smaller previous donors, Exley (2015) documents more excuse-driven responses to risk among those who give less when there is no risk, and Exley (2016) finds more excuse-driven responses to lower-rated charities among those who give less to the highest-rated charities. ${ }^{25}$

\footnotetext{
${ }^{22}$ Gender is also an interesting dimension to consider when considering heterogeneity in prosocial behavior. While we are underpowered to detect differences by gender (with our sample consisting of $83 \%$ females), Appendix Tables A.3 provides some qualitative evidence for females being more responsive to the treatment manipulations. This echoes the results from DellaVigna et al. (2013), as they find that women are more likely to avoid the ask when it is easier to do so. More broadly, women may be more likely to be marginal givers and thus susceptible to excuses.

${ }^{23}$ This is seen by us failing to reject that the sum of coefficients on Expected Ask and Expected Ask ${ }^{*}$ Previous Supporter is statistically different than 0 in Column (1) of Appendix Table A.2 $(p=0.20)$.

${ }^{24}$ There is also some evidence that previous supporters are less responsive to the provision of information, perhaps because previous supporters are more familiar with the available information on how their votedfor group rescues dogs. While unavoidable information has a negative level effect among new supporters, unavoidable information is significantly less detrimental to previous supporters and does not significantly influence their click-through rates (Unavoidable Info + Unavoidable Info*Previous Supporter $=0$ is not rejected, $p=0.94)$.

${ }^{25}$ Similarly, in the voting literature, Gerber and Rogers (2009) observe that messages about low-voterturnout, relative to high-voter-turnout, are most counterproductive among infrequent voters.
} 


\subsection{Treatment Effects and Information Acquisition}

Information acquisition choices in the Avoidable Information treatments are such that individuals more readily avoid prosocial behavior when the ask is expected. This section further considers whether evidence - related to both extensive margin decisions about whether to reveal the information and intensive margin decisions about how to consider the information when revealed - is consistent with motivated reasoning.

The motivated information avoidance literature suggests viewing decisions will be affected at the extensive margin. Individuals may avoid viewing information in order to choose a more selfish action without having to bear the cost from knowing the extent to which that action is selfish or the extent to which an alternative action is prosocial. Avoidance is common when the ask is unexpected in our study: the revelation rate is only 0.18 among new supporters and 0.25 among previous supporters. Avoidance is even more likely when the ask is expected: the revelation rate drops to 0.13 among new supporters and 0.21 among previous supporters. That is, expecting the ask causes a $28 \%$ decrease in revealing information among new supporters and a $18 \%$ decrease among previous supporters. The first two columns of Appendix Table A.4 confirm these drops for both new and previous supporters, although qualitatively less so among the latter. ${ }^{26}$

The motivated information processing literature suggests viewing decisions will also be affected on the intensive margin. Individuals may distort information in a self-serving manner when they may benefit from doing so. For instance, to provide a justification for a selfish choice, they may overweight information that aligns with the selfish choice and underweight information that runs counter to the selfish choice. Unlike the extensive margin though, there is no clear measure of individuals' intensive margin viewing decisions. In focusing on one observable measure - the amount of time individuals spend viewing the information - the last two columns of Appendix Table A.4 show that viewing time is not significantly different when the ask is expected or unexpected.

However, conditional on revealing the information, Appendix Table A.5 demonstrates that viewing time behavior may be more nuanced. Among individuals who choose to reveal the information when the ask is unexpected, both new supporters and previous supporters who click-through spend more time viewing the information than their counterparts who do not click-through. ${ }^{27}$ This pattern may reasonably arise because individuals who support the organization are more likely both to spend time reading information and to click-through. Suggestively, a similar pattern does not emerge when the ask is instead expected. There

\footnotetext{
${ }^{26}$ For previous supporters, the significant negative impact of expecting the ask is seen by us rejecting that the sum of the coefficients on Expected Ask and Expected Ask*Previous Supporter equals 0 in Column (1) of Appendix Table A.4 ( $p=0.03)$.

${ }^{27}$ A similar pattern emerges in the Unavoidable Information treatments (see Appendix Tables A.6).
} 
is less time spent viewing the information among individuals who click-through (generoustypes) and more time spent viewing among individuals who do not click through (selfishtypes). The generous-fast finding is particularly striking among previous supporters while the selfish-slow finding is more striking among new supporters. In addition to supporting the possibility that new supporters are more likely to be excuse-driven than previous supporters, this finding is consistent with the broader empirical findings where prosocial tendencies are intuitive and fast while selfish choices are deliberate and slow (see Zaki and Mitchell (2013) for a review or Rand, Greene and Nowak (2012) for an example). ${ }^{28}$

\section{Complementary Online Studies}

To further investigate the robustness of our findings, we conducted two complementary online studies on Amazon Mechanical Turk. ${ }^{29}$ The main advantage of this setting is the ability to collect donation data. A noteworthy disadvantage of this setting is that participants are aware that they are part of (and indeed consent to being part of) an academic study. ${ }^{30}$

For these two studies, we recruited 2,300 participants via Amazon Mechanical Turk to complete one of two complementary studies. Eligible participants - anyone who resided in the United States and had completed 100 tasks via this platform with an approval rating of $95 \%$ or better - saw our study description as "You will be asked to answer a 5 minute academic survey" and knew the guaranteed payment was $\$ 1$ for completing the survey. Only one participant failed to complete the study for which they were recruited, resulting in a total sample size of 2,299. ${ }^{31}$ Screenshots for the two studies are in Appendix B.

The "main" online study $(\mathrm{n}=1,500)$ randomly assigns participants to one of three treatments, and the "unavoidable ask" online study $(n=799)$ randomly assigns participants to one of two treatments. ${ }^{32}$ The Expected Ask treatment and Unexpected Ask treatment in the main online study most closely follow the design from the No Information treatments in

\footnotetext{
${ }^{28}$ Our heterogeneous findings also relate to the literature that considers how confounds may influence the relationship between decision time and prosocial tendencies. For instance, the relationship may depend on the selection of individuals (Tinghög et al., 2013), the complexity of the environment (Recalde, Riedl and Vesterlund, 2014), or the strength of preferences over the available choice set (Krajbich et al., 2015). Indeed, Kessler, Kivimaki and Niederle (2015) show that more time corresponds with reduced giving when the benefits of giving are low but increased giving if the benefits of giving are high.

${ }^{29}$ For more details about Amazon Mechanical Turk, recent papers investigating this platform include Paolacci, Chandler and Ipeirotis (2010) and Horton, Rand and Zeckhauser (2011).

${ }^{30}$ One could, in principle, be concerned that we could not create an unexpected ask in such a setting. Results in Appendix C, however, provide evidence for participants being twice as likely to expect an ask in this setting when consider the Expected Ask treatment versus the Unexpected Ask treatment.

${ }^{31}$ This participant submitted an (invalidated) complete code and did not finish our survey. If we also consider participants who did not submit a completion, 23 out of 3,022 participants (less than 1\%) did not complete our survey.

${ }^{32}$ We ran our unavoidable ask online study in April 2016, and after helpful feedback from anonymous referees, we ran our main online study in June 2017.
} 
our field study. Thus, we will begin by detailing these two treatments and then will briefly discuss the results from the remaining treatment in the main online study as well as from the unavoidable ask online study.

The design for the Unexpected Ask treatment and Expected Ask treatment in main online study involves two decisions. In the first decision, participants are asked to vote for one of eight charities. ${ }^{33}$ They learn that the charity with the most votes will receive a donation of $\$ 100$, and additionally, the charity voted for by a randomly selected participant will receive a donation of $\$ 25$.

After making their first decision but before viewing their second decision, participants read the following text according to whether they are randomly assigned to either the Unexpected Ask treatment or the Expected Ask treatment.

Unexpected Ask: "Thank you for voting for [group name]! On the next page, complete your second decision in this study."

Expected Ask: "Thank you for voting for [group name]! On the next page, complete your second decision in this study, and if you would like to, donate to [group name]."

In the second decision, participants are informed of an additional 100 cents in bonus payment that they may receive. Participants then face a "donation opportunity ask" where they must indicate if they would like to have the opportunity to donate some of this bonus payment to their voted-for charity. If participants indicate that they do not want an opportunity to donate, their decisions are complete and they are taken to a brief follow-up survey. If instead participants indicate that they would like an opportunity to donate, they then face a "donation ask" on a subsequent page that requires them to indicate how much of their bonus (in cents) they would like to keep for themselves and how much they would instead like to donate to their voted-for charity. The amounts to oneself and the charity had to sum to 100 cents. ${ }^{34}$ The study then concludes with a follow-up survey.

Table 2 presents our main results via a linear probability model of the likelihood to clickthrough on expecting the ask, both when controls are not included and when controls are included. Columns (1) and (2) show that choosing to proceed to the donation opportunity is nearly perfectly correlated with subsequently making a donation. This result supports the possibility that individuals who indicate that they would like to donate, such as those

\footnotetext{
${ }^{33}$ Selecting from the top-ten most followed and the top-ten super-sized charities on Charity Navigator, the eight charities that individuals could vote for include ALSAC - St. Jude Children's Research Hospital, American Cancer Society, City of Hope, Oxfam America, Smithsonian Institution, The Nature Conservancy, World Vision, and World Wildlife Fund.

${ }^{34}$ Participants otherwise view an error message and are redirected to answer this question again.
} 
participants who click-through to the donation page for their favorite animal group in our field study, are likely to subsequently donate. ${ }^{35}$ Columns (3) and (4) replicate our main finding from our field study but with donation data instead of click-through data: expecting the ask causes donation rates to significantly decrease by 6 percentage points. Indeed, since the donation rate is 0.62 when the ask is unexpected and 0.56 when the ask is expected, this corresponds with a $10 \%$ decrease in the donation rate.

Table 2: Donation regressions from our main online study

\begin{tabular}{lcccc}
\hline \hline & \multicolumn{3}{c}{ Linear probability model of donation } \\
& $(1)$ & $(2)$ & $(3)$ & $(4)$ \\
\hline Click-through to donation opportunity & $0.99^{* * *}$ & $1.00^{* * *}$ & & \\
& $(0.00)$ & $(0.00)$ & & \\
Expected Ask & & & & \\
& -0.00 & -0.00 & $-0.06^{* *}$ & $-0.06^{* *}$ \\
Constant & $(0.00)$ & $(0.00)$ & $(0.03)$ & $(0.03)$ \\
& & & & \\
Controls & 0.00 & -0.06 & $0.62^{* * *}$ & $0.53^{* * *}$ \\
Observations & $(0.00)$ & $(0.05)$ & $(0.02)$ & $(0.17)$ \\
Donation rates & no & yes & no & yes \\
\hline \hline
\end{tabular}

${ }^{*} p<0.10,{ }^{* *} p<0.05,{ }^{* * *} p<0.01$. Standard errors are clustered at the voted-for charity level and shown in parentheses. The results are from OLS regressions of donations to voted-for charity. Data include results from the Unexpected Ask treatment and Expected Ask treatment of our main online study. Click-through to donation opportunity is an indicator for participants who indicate that they would like an opportunity to donate when faced with the "donation opportunity ask." Expected Ask is an indicator for when the ask is expected. Controls include indicators for each selected animal groups, previous supporters, and males. Controls also include self-reports about whether participants answered questions carefully, answered questions randomly, understood the study, have ever volunteered for a charity, or have ever donated to a charity.

Appendix Table A.7 provides two additional set of results that arise when considering all treatments involved in either of our online studies. The first set of results relates to the third treatment of the main online study, the Rephrased Expected Ask treatment, in which the "if you want to, donate" phrasing in the expected ask message is replaced with a more neutral phrasing of "decide whether to donate" (see Panel C in Appendix Figure B.2). ${ }^{36}$ Columns (1) - (2) of Appendix Table A.7 show that this rephrased expected ask directionally,

\footnotetext{
${ }^{35}$ Of course, the participants and environment in our online study are different than the participants and environment in our field study, so this is only supportive evidence.

${ }^{36}$ As mentioned in footnote 32 , we incorporated helpful feedback from the referees on our unavoidable ask online study to more closely match our field study when subsequently running our main online study. Since our unavoidable ask online study only ran the Rephrased Expected Ask treatment and the Unexpected Ask treatment, we also ran the Rephrased Expected Ask treatment in our main online study. This rephrased message could increase the difficulty with which participants can justify declining the ask if, for instance, it seems less socially acceptable to decline the ask absent the "if you want to, donate" phrase.
} 
although insignificantly, reduces the negative impact of expecting the ask on the probability of donating. The second set of results examines the impact of expecting the ask in our unavoidable ask online study, in which the "donation ask opportunity" question is removed so that participants cannot avoid the donation ask in their second decision (see Panel $\mathrm{C}$ in Appendix Figure B.3). Columns (3) and (4) of Appendix Table A.7 show that making the donation ask unavoidable directionally, although insignificantly, reduces the negative impact of expecting the ask on the probability of donating. Moreover, as seen in prior literature on the avoidance of the ask, making the donation ask unavoidable causes overall donation rates to substantially and significantly increase.

\section{Conclusion}

Gino, Norton and Weber (2016) conclude their survey paper by noting that self-serving behavior is likely when individuals have "flexibility and creativity in how they acquire, attend to, and process information." This paper extends the literature by documenting evidence for a reluctance to be prosocial in an environment that does not provide flexibility that may arise when the ask can be avoided, when information can easily be distorted, or when uncertainty in outcomes can be exploited.

In a large field experiment using an online voting contest, we vary whether an upcoming donation ask is announced and expected or a surprise and (more) unexpected. We document a significant $22 \%$ reduction in click-through rates to a donation page (from 0.51 to 0.40 ) when individuals know an ask is coming. Our complementary online experiments confirm that this effect extends to donation data.

In other words, our findings show how expecting an imminent ask, and thus having the brief opportunity to find ways to decline it, is detrimental to prosocial behavior. This suggests a powerful approach to bolstering prosocial behavior: surprise individuals with asks to be prosocial. ${ }^{37}$ Future work may consider the benefits to allowing for an unexpected ask as weighed against the benefits to other approaches that may eliminate the ability for an unexpected ask, such as information campaigns on why to support a charity. Future work may further examine if the finding that expected asks are easier to decline carries over to other contexts and yields different policy prescriptions. Limiting the ability to develop ways to decline an ask may be desirable in some contexts, such as when declining the ask impedes achieving Pareto-optimal coordination. Instead facilitating ways to decline the ask may be desirable in other contexts, for instance, if declining the ask helps to mitigate the gender gap in non-promotable tasks at work (Vesterlund et al., 2015).

\footnotetext{
${ }^{37}$ Other approaches may also involve interventions that encourage participants to evaluate a situation when self-serving motives are not present before following-up with a related prosocial ask (see such manipulations in Babcock et al. (1995), Haisley and Weber (2010) and Gneezy et al. (2016)).
} 


\section{References}

Andreoni, James, and B. Douglas Bernheim. 2009. "Social Image and the 50-50 Norm: A Theoretical and Experimental Analysis of Audience Effects." Econometrica, 77(5): 1607-1636.

Andreoni, James, and Justin M. Rao. 2011. "The power of asking: How communication affects selfishness, empathy, and altruism." Journal of Public Economics, 95: 513-520.

Andreoni, James, Justin M. Rao, and Hannah Trachtman. 2016. "Avoiding the ask: A field experiment on altruism, empathy, and charitable giving." Journal of Political Economy.

Babcock, Linda, George Loewenstein, Samuel Issacharoff, and Colin Camerer. 1995. "Biased Judgments of Fairness in Bargaining." The American Economic Review, 85(5): 1337-1343.

Bartling, Björn, and Urs Fischbacher. 2012. "Shifting the Blame: On Delegation and Responsibility." Review of Economic Studies, 79(1): 67-87.

Bartling, Björn, Florian Engl, and Roberto A. Weber. 2014. "Does willful ignorance deflect punishment? - An experimental study." European Economic Review, 70(0): 512 524 .

Batista, Catia, Dan Silverman, and Dean Yang. 2015. "Directed Giving: Evidence from an Inter-Household Transfer Experiment." Journal of Economic Behavior $\& 3$ Organization.

Broberg, Tomas, Tore Ellingsen, and Magnus Johannesson. 2007. "Is generosity involuntary?" Economics Letters, 94(1): 32-37.

Brown, Alexander L., Jonathan Meer, and J. Forrest Williams. 2014. "Social Distance and Quality Ratings in Charity Choice." NBER Working Paper Series.

Castillo, Marco, Ragan Petrie, and Clarence Wardell. 2014. "Fundraising through online social networks: A field experiment on peer-to-peer solicitation." Journal of Public Economcis, 29-35.

Castillo, Marco, Ragan Petrie, and Clarence Wardell. 2017. "Friends Asking Friends for Charity: The Importance of Gifts and Audience." Working Paper. 
Coffman, Lucas C. 2011. "Intermediation Reduces Punishment (and Reward)." American Economic Journal: Microeconomics, 3(4): 1-30.

Dana, Jason, Daylian M. Cain, and Robyn M. Dawes. 2006. "What you don't know won't hurt me: Costly (but quiet) exit in dictator games." Organizational Behavior and Human Decision Processes, 100: 193-201.

Dana, Jason, Roberto A. Weber, and Jason Xi Kuang. 2007. "Exploiting moral wiggle room: experiments demonstrating an illusory preference for fairness." Economic Theory, 33: 67-80.

Danilov, Anastasia, and Silvia Saccardo. 2016. "Disguised Discrimination." Working Paper.

DellaVigna, Stefano, John List, and Ulrike Malmendier. 2012. "Testing for Altruism and Social Pressure in Charitable Giving." Quarterly Journal of Economics, 127(1): 1-56.

DellaVigna, Stefano, John List, Ulrike Malmendier, and Gautam Rao. 2013. "The Importance of Being Marginal: Gender Differences in Generosity." American Economic Review, 103(3): 586-590.

Di Tella, Rafael, Ricardo Perez-Truglia, Andres Babino, and Mariano Sigman. 2015. "Conveniently Upset: Avoiding Altruism by Distorting Beliefs about Others' Altruism." American Economic Review, 105(11): 3416-42.

Eckel, Catherine, and Phillip Grossman. 2008. "Subsidizing charitable contributions: a natural field experiment comparing matching and rebate subsidies." Experimental Economics, 11(3): 234-252.

Exley, Christine L. 2015. "Excusing Selfishness in Charitable Giving: The Role of Risk." Review of Economic Studies, 83(2): 587-628.

Exley, Christine L. 2016. "Using Charity Performance Metrics as an Excuse Not To Give." Working Paper.

Exley, Christine L. Forthcoming. "Incentives for Prosocial Behavior: The Role of Reputations." Management Science.

Falk, Armin, and Nora Szech. 2013. "Organizations, Diffused Pivotality and Immoral Outcomes." IZA Discussion Paper 7442. 
Fong, Christina M., and Felix Oberholzer-Gee. 2011. "Truth in giving: Experimental evidence on the welfare effects of informed giving to the poor." Journal of Public Economics, 95: 436-444.

Garbarino, Ellen, Robert Slonim, and Marie Claire Villeval. 2016. "Loss Aversion and Lying Behavior: Plus a method to estimate lying." Working Paper.

Gerber, Alan S., and Todd Rogers. 2009. "Descriptive social norms and motivation to vote: Everybody's voting and so should you." The Journal of Politics, 71(1): 178-191.

Gino, Francesca, Michael I. Norton, and Roberto A. Weber. 2016. "Motivated Bayesians: Feeling Moral While Acting Egoistically Motivated Bayesians: Feeling Moral While Acting Egoistically Motivated Bayesians: Feeling Moral While Acting Egotistically." Journal of Economic Perspectives, 30(3): 189-212.

Giving USA Foundation. 2015. "Giving USA 2015: The Annual Report on Philanthropy." Indiana University Lilly Family School of Philanthropy.

Gneezy, Ayelet, Alex Imas, Amber Brown, Leif D. Nelson, and Michael I. Norton. 2012. "Paying to Be Nice: Consistency and Costly Prosocial Behavior." Management Science, 58(1): 179-187.

Gneezy, Uri, Elizabeth A. Keenan, and Ayelet Gneezy. 2014. "Avoiding overhead aversion in charity." Science, 346(6209): 632-635.

Gneezy, Uri, Silvia Saccardo, Marta Serra-Garcia, and Roel van Veldhuizen. 2016. "Motivated Self-Deception, Identity, and Unethical Behavior." Working paper.

Golman, Russell, David Hagmann, and George Loewenstein. 2017. "Information Avoidance." Journal of Economic Literature, 55(1): 1-40.

Grossman, Zachary. 2014. "Strategic ignorance and the robustness of social preferences." Management Science, 60(11): 2659-2665.

Grossman, Zachary, and Joël J van der Weele. 2016. "Self-image and willful ignroance in social decisions." Journal of the European Economic Association.

Haisley, Emily C., and Roberto A. Weber. 2010. "Self-serving interpretations of ambiguity in other-regarding behavior." Games and Economic Behavior, 68: 614-625. 
Hamman, John R., George Loewenstein, and Roberto A. Weber. 2010. "SelfInterest through Delegation: An Additional Rationale for the Principal-Agent Relationship." American Economic Review, 100(4): 1826-1846.

Horton, John J., David G. Rand, and Richard J. Zeckhauser. 2011. "The online laboratory: Conducting experiments in a real labor marke." Experimental Economics, 14(3): 399-425.

Hsee, Christopher K. 1995. "Elastic justification: How tempting but task-irrelevant factors influence decisions." Organizational Behavioral and Human Decision Process, 62(3).

Hsee, Christopher K. 1996. "Elastic justification: How unjustifiable factors influence judgments." Organizational Behavior and Human Decision Processes, , (1).

Huck, Steffen, and Imran Rasul. 2011. "Matched fundraising: Evidence from a natural field experiment." Journal of Public Economics, 95: 351-362.

Hwang, Hokyu, and Walter W. Powell. 2009. "The Rationalization of Charity: The Influences of Professionalism in the Nonprofit Sector." Administrative Science Quarterly, 54: $268-298$.

Kamdar, Amee, Steven D. Levitt, John A. List, Brian Mullaney, and Chad Syverson. 2015. "Once and Done: Leveraging Behavioral Economics to Increase Charitable Contributions."

Karlan, Dean, and Daniel H. Wood. 2017. "The effect of effectiveness: donor response to aid effectiveness in a direct mail fundraising experiment." Journal of Behavioral and Experimental Economics, 66: 1-8.

Karlan, Dean, and John A. List. 2007. "Does Price Matter in Charitable Giving? Evidence from a Large-Scale Natural Field Experiment." The American Economic Review, 97(5): pp. 1774-1793.

Karlan, Dean, John List, and Eldar Shafir. 2011. "Small matches and charitable giving: Evidence from a natural field experiment." Journal of Public Economics, 95(5): 344-350.

Kessler, Judd, Hannu Kivimaki, and Muriel Niederle. 2015. "Generosity Over Time." Working Paper.

Klinowski, David. 2015. "Reluctant donors and their reactions to social information." Working paper. 
Konow, James. 2000. "Fair Shares: Accountability and Cognitive Dissonance in Allocation Decisions." The American Economic Review, 90(4): 1072-1092.

Krajbich, Ian, Bjorn Bartling, Todd Hare, and Ernst Fehr. 2015. "Rethinking fast and slow based on a critique of reaction-time reverse inference." Nature Communications.

Lacetera, Nicola, Mario Macis, and Robert Slonim. 2014. "Rewarding Volunteers: A Field Experiment." Management Science, 1-23.

Lazear, Edward P., Ulrike Malmendier, and Roberto A. Weber. 2012. "Sorting in experiments with application to social preferences." American Economic Journal: Applied Economics, 4(1): 136-163.

Lilley, Matthew, and Robert Slonim. 2016. "Gender Differences in Altruism: Responses to a Natural Disaster." IZA Discussion Paper No. $965 \%$.

Linardi, Sera, and Margaret A. McConnell. 2011. "No excuses for good behavior: Volunteering and the social environment." Journal of Public Economics, 95: 445-454.

Lin, Stephanie C., Rebecca L. Schaumberg, and Taly Reich. 2016. "Sidestepping the rock and the hard place: The private avoidance of prosocial requests." Journal of Experimental Social Psychology, 35-40.

Li, Sherry Xin, Catherine Eckel, Philip J. Grossman, and Tara Larson Brown. 2015. "Directed giving enhances voluntary giving to government." Economics Letters, 133: $51-54$.

Meer, Jonathan. 2011. "Brother, can you spare a dime? Peer pressure in charitable solicitation." Journal of Public Economics, 95(7): 926-941.

Meer, Jonathan. 2014. "Effects of the price of charitable giving: Evidence from an online crowdfunding platform." Journal of Economic Behavior $\&$ Organization, 103: 113-124.

Miller, Dale T., and Benoît Monin. 2016. "Moral opportunities versus moral tests." In The Social Psychology of Morality. , ed. \& P. van Lange J. Forgas, L. Jussim. New York:Psychology Press.

Nickerson, David, and Todd Rogers. 2014. "Political Campaigns and Big Data." Journal of Economic Perspectives, 28: 51-74.

Niesse-Ruenzi, Alexandra, Martin Weber, and David Michael Becker. 2014. "To pay or not to pay - Evidence from whole blood donations in Germany." Working paper. 
Norton, Michael I, Joseph A Vandello, and John M Darley. 2004. "Casuistry and social category bias." Journal of personality and social psychology, 87(6): 817-831.

Paolacci, Gabriele, Jesse Chandler, and Panagiotis G. Ipeirotis. 2010. "Running experiments on amazon mechanical turk." Judgment and Decision making, 5(5): 411-419.

Rand, David G., Joshua D. Greene, and Martin A. Nowak. 2012. "Spontaneous giving and calculated greed." Nature, 489(7416): 427-430.

Recalde, Maria P., Arno Riedl, and Lise Vesterlund. 2014. "Error prone inference from response time: The case of intuitive generosity." Working Paper.

Schwardman, Peter, and Joël van der Weele. 2016. "Deception and Self-Deception." Tinbergen Institute Discussion Paper.

Shalvi, Shaul, Jason Dana, Michel JJ Handgraaf, and Carsten KW De Dreu. 2011. "Justified ethicality: Observing desired counterfactuals modifies ethical perceptions and behavior." Organizational Behavior and Human Decision Processes, 115(2): 181-190.

Snyder, Melvin L, Robert E Kleck, Angelo Strenta, and Steven J Mentzer. 1979. "Avoidance of the handicapped: an attributional ambiguity analysis." Journal of personality and social psychology, 37(12): 2297-2306.

Tinghög, Gustav, David Andersson, Caroline Bonn, Harald Böttiger, Camilla Josephson, Gustaf Lundgren, Daniel Västfjäll, Michael Kirchler, and Magnus Johannesson. 2013. "Intuition and cooperation reconsidered." Nature, 498(7452): E1-E2.

Trachtman, Hannah, Andrew Steinkruger, Mackenzie Wood, Adam Wooster, James Andreoni, James J. Murphy, and Justin M. Rao. 2015. "Fair weather avoidance: unpacking the costs and benefits of "Avoiding the Ask"." Journal of the Economic Science Association, 1-7.

van der Weele, Joël J. 2014. "Inconvenient Truths: Determinants of Strategic Ignorance in Moral Dilemmas." Working paper.

Vesterlund, Lise, Linda Babcock, Maria Recalde, and Laurie Weinbart. 2015. "Breaking the Glass Ceiling with "No": Gender Differences in Accepting and Receiving Requests for Non-Promotable Tasks." Working Paper.

Yörük, Bariş K. 2016. "Charity Ratings." ournal of Economics $\& 3$ Management Strategy, 25(1): 195-219. 
Zaki, Jamil, and Jason P. Mitchell. 2013. "Intuitive prosociality." Current Directions in Psychological Science, 22(6): 466-470. 


\section{A Field Study}

Table A.1: Fraction of participants who have interacted with voted-for group in following ways

\begin{tabular}{lccccccc}
\hline \hline Information & Any & \multicolumn{2}{c}{ None } & \multicolumn{3}{c}{ Unavoidable } & \multicolumn{2}{c}{ Avoidable } \\
Expected Ask & & yes & no & yes & no & yes & no \\
\hline Adopter & 0.26 & 0.28 & 0.28 & 0.27 & 0.23 & 0.28 & 0.24 \\
Donor & 0.22 & 0.24 & 0.21 & 0.22 & 0.23 & 0.23 & 0.21 \\
Attendee of Event & 0.17 & 0.17 & 0.18 & 0.17 & 0.16 & 0.18 & 0.16 \\
Volunteer & 0.15 & 0.16 & 0.15 & 0.14 & 0.13 & 0.16 & 0.13 \\
User of Services & 0.10 & 0.09 & 0.10 & 0.10 & 0.10 & 0.11 & 0.10 \\
Staff & 0.01 & 0.02 & 0.01 & 0.02 & 0.01 & 0.01 & 0.01 \\
Interacted in Other Way & 0.44 & 0.43 & 0.42 & 0.44 & 0.43 & 0.43 & 0.46 \\
Have Never Interacted & 0.07 & 0.07 & 0.06 & 0.07 & 0.08 & 0.07 & 0.07 \\
Previous Supporter & 0.54 & 0.55 & 0.56 & 0.55 & 0.53 & 0.55 & 0.52 \\
New Supporter & 0.46 & 0.45 & 0.44 & 0.45 & 0.47 & 0.45 & 0.48 \\
Female & 0.83 & 0.85 & 0.82 & 0.83 & 0.82 & 0.82 & 0.84 \\
Male & 0.14 & 0.13 & 0.15 & 0.13 & 0.14 & 0.13 & 0.14 \\
Gender Unknown & 0.03 & 0.02 & 0.04 & 0.03 & 0.04 & 0.04 & 0.02 \\
\hline Observations & 5976 & 991 & 1001 & 1005 & 980 & 1000 & 999 \\
\hline \hline
\end{tabular}

The first eight rows indicate the frequency with which the shown answers were provided in response to how a participant knew the animal shelter for which they voted. A previous supporter is any individual who indicated that they were an adopter, donor, volunteer, attendee of event, user of services or staff. A new supporter is anyone who did not indicate one of the aforementioned ways of knowing the animal group for which they voted. Computer code that predicts gender from names was used to classify participants as female or male, or unknown gender. 
Table A.2: By type of supporter, click-through regressions

\begin{tabular}{|c|c|c|c|c|c|c|}
\hline \multirow{3}{*}{ Information: } & \multicolumn{6}{|c|}{ Linear probability model of click-through } \\
\hline & \multicolumn{2}{|c|}{ None } & \multicolumn{2}{|c|}{ None or Unavoidable } & \multicolumn{2}{|c|}{ None or Avoidable } \\
\hline & $(1)$ & $(2)$ & $(3)$ & $(4)$ & $(5)$ & $(6)$ \\
\hline Expected Ask & $\begin{array}{c}-0.16^{* * *} \\
(0.02)\end{array}$ & $\begin{array}{c}-0.16^{* * *} \\
(0.02)\end{array}$ & $\begin{array}{c}-0.16^{* * *} \\
(0.02)\end{array}$ & $\begin{array}{c}-0.16^{* * *} \\
(0.02)\end{array}$ & $\begin{array}{c}-0.16^{* * *} \\
(0.02)\end{array}$ & $\begin{array}{c}-0.16^{* * *} \\
(0.02)\end{array}$ \\
\hline Unavoidable Info & & & $\begin{array}{c}-0.09^{* * *} \\
(0.02)\end{array}$ & $\begin{array}{c}-0.09^{* * *} \\
(0.02)\end{array}$ & & \\
\hline $\begin{array}{l}\text { Expected Ask } \\
* \text { Unavoidable Info }\end{array}$ & & & $\begin{array}{c}0.15^{* * *} \\
(0.02)\end{array}$ & $\begin{array}{c}0.15^{* * *} \\
(0.02)\end{array}$ & & \\
\hline Avoidable Info & & & & & $\begin{array}{c}-0.06^{* *} \\
(0.02)\end{array}$ & $\begin{array}{c}-0.07^{* *} \\
(0.02)\end{array}$ \\
\hline $\begin{array}{l}\text { Expected Ask } \\
\text { * Avoidable Info }\end{array}$ & & & & & $\begin{array}{l}0.09^{* *} \\
(0.04)\end{array}$ & $\begin{array}{l}0.09^{* *} \\
(0.04)\end{array}$ \\
\hline Previous Supporter & $\begin{array}{l}-0.04 \\
(0.04)\end{array}$ & $\begin{array}{l}-0.00 \\
(0.04)\end{array}$ & $\begin{array}{l}-0.04 \\
(0.04)\end{array}$ & $\begin{array}{c}0.00 \\
(0.04)\end{array}$ & $\begin{array}{l}-0.04 \\
(0.04)\end{array}$ & $\begin{array}{l}-0.00 \\
(0.04)\end{array}$ \\
\hline $\begin{array}{l}\text { Expected Ask } \\
\text { * Previous Supporter }\end{array}$ & $\begin{array}{c}0.09 \\
(0.05)\end{array}$ & $\begin{array}{c}0.09 \\
(0.05)\end{array}$ & $\begin{array}{c}0.09 \\
(0.05)\end{array}$ & $\begin{array}{c}0.09 \\
(0.05)\end{array}$ & $\begin{array}{c}0.09 \\
(0.05)\end{array}$ & $\begin{array}{c}0.09 \\
(0.05)\end{array}$ \\
\hline $\begin{array}{l}\text { Unavoidable Info } \\
\text { * Previous Supporter }\end{array}$ & & & $\begin{array}{l}0.09^{* *} \\
(0.04)\end{array}$ & $\begin{array}{l}0.09^{* *} \\
(0.04)\end{array}$ & & \\
\hline $\begin{array}{l}\text { Expected Ask } \\
\text { * Unavoidable Info } \\
\text { * Previous Supporter }\end{array}$ & & & $\begin{array}{l}-0.08 \\
(0.06)\end{array}$ & $\begin{array}{l}-0.08 \\
(0.06)\end{array}$ & & \\
\hline $\begin{array}{l}\text { Avoidable Info } \\
\text { * Previous Supporter }\end{array}$ & & & & & $\begin{array}{c}0.06 \\
(0.04)\end{array}$ & $\begin{array}{c}0.07 \\
(0.04)\end{array}$ \\
\hline $\begin{array}{l}\text { Expected Ask } \\
\text { * Avoidable Info } \\
\text { * Previous Supporter }\end{array}$ & & & & & $\begin{array}{l}-0.10 \\
(0.06)\end{array}$ & $\begin{array}{l}-0.10 \\
(0.06)\end{array}$ \\
\hline Constant & $\begin{array}{c}0.53^{* * *} \\
(0.02)\end{array}$ & $\begin{array}{c}0.46^{* * *} \\
(0.04)\end{array}$ & $\begin{array}{c}0.53^{* * *} \\
(0.02)\end{array}$ & $\begin{array}{c}0.49^{* * *} \\
(0.05)\end{array}$ & $\begin{array}{c}0.53^{* * *} \\
(0.02)\end{array}$ & $\begin{array}{c}0.46^{* * *} \\
(0.02)\end{array}$ \\
\hline Controls & no & yes & no & yes & no & yes \\
\hline Observations & 1989 & 1989 & 3973 & 3973 & 3987 & 3987 \\
\hline Click-through rates & 0.46 & 0.46 & 0.46 & 0.46 & 0.45 & 0.45 \\
\hline
\end{tabular}

${ }^{*} p<0.10,{ }^{* *} p<0.05,{ }^{* * *} p<0.01$. Standard errors are clustered at the voted-for animal group level and shown in parentheses. The results are from a linear probability model of likelihood to click-through to the donation page of voted-for animal group. Expected Ask, Unavoidable Info, Avoidable Info, and Previous Supporters are indicators for when the ask is expected, the information provided is unavoidable, the information provided is avoidable, and previous supporters. Controls include indicators for each individual's day that they voted during the contest, selected animal groups, and males. 
Table A.3: By gender, click-through regressions

\begin{tabular}{|c|c|c|c|c|c|c|}
\hline \multirow{3}{*}{ Information: } & \multicolumn{6}{|c|}{ Linear probability model of click-through } \\
\hline & \multicolumn{2}{|c|}{ None } & \multicolumn{2}{|c|}{ None or Unavoidable } & \multicolumn{2}{|c|}{ None or Avoidable } \\
\hline & $(1)$ & $(2)$ & $(3)$ & $(4)$ & $(5)$ & $(6)$ \\
\hline Expected Ask & $\begin{array}{c}-0.11^{* * *} \\
(0.03)\end{array}$ & $\begin{array}{c}-0.11^{* *} \\
(0.03)\end{array}$ & $\begin{array}{c}-0.11^{* * *} \\
(0.03)\end{array}$ & $\begin{array}{c}-0.11^{* * *} \\
(0.03)\end{array}$ & $\begin{array}{c}-0.11^{* * *} \\
(0.03)\end{array}$ & $\begin{array}{c}-0.11^{* * *} \\
(0.03)\end{array}$ \\
\hline Unavoidable Info & & & $\begin{array}{l}-0.05 \\
(0.03)\end{array}$ & $\begin{array}{l}-0.04 \\
(0.03)\end{array}$ & & \\
\hline $\begin{array}{l}\text { Expected Ask } \\
* \text { Unavoidable Info }\end{array}$ & & & $\begin{array}{l}0.10^{* *} \\
(0.03)\end{array}$ & $\begin{array}{l}0.10^{* *} \\
(0.03)\end{array}$ & & \\
\hline Avoidable Info & & & & & $\begin{array}{l}-0.04^{*} \\
(0.02)\end{array}$ & $\begin{array}{l}-0.04^{*} \\
(0.02)\end{array}$ \\
\hline $\begin{array}{l}\text { Expected Ask } \\
* \text { Avoidable Info }\end{array}$ & & & & & $\begin{array}{c}0.05 \\
(0.03)\end{array}$ & $\begin{array}{c}0.04 \\
(0.03)\end{array}$ \\
\hline Male & $\begin{array}{l}-0.05 \\
(0.03)\end{array}$ & $\begin{array}{l}-0.05 \\
(0.03)\end{array}$ & $\begin{array}{l}-0.05 \\
(0.03)\end{array}$ & $\begin{array}{l}-0.05 \\
(0.03)\end{array}$ & $\begin{array}{l}-0.05 \\
(0.03)\end{array}$ & $\begin{array}{l}-0.05 \\
(0.03)\end{array}$ \\
\hline $\begin{array}{l}\text { Expected Ask } \\
* \text { Male }\end{array}$ & $\begin{array}{c}0.04 \\
(0.06)\end{array}$ & $\begin{array}{c}0.02 \\
(0.06)\end{array}$ & $\begin{array}{c}0.04 \\
(0.06)\end{array}$ & $\begin{array}{c}0.03 \\
(0.06)\end{array}$ & $\begin{array}{c}0.04 \\
(0.06)\end{array}$ & $\begin{array}{c}0.03 \\
(0.06)\end{array}$ \\
\hline $\begin{array}{l}\text { Unavoidable Information } \\
* \text { Male }\end{array}$ & & & $\begin{array}{c}0.05 \\
(0.05)\end{array}$ & $\begin{array}{c}0.05 \\
(0.05)\end{array}$ & & \\
\hline $\begin{array}{l}\text { Expected Ask } \\
\text { * Unavoidable Information } \\
\text { * Male }\end{array}$ & & & $\begin{array}{c}0.03 \\
(0.09)\end{array}$ & $\begin{array}{c}0.04 \\
(0.09)\end{array}$ & & \\
\hline $\begin{array}{l}\text { Avoidable Information } \\
* \text { Male }\end{array}$ & & & & & $\begin{array}{c}0.08 \\
(0.06)\end{array}$ & $\begin{array}{c}0.09 \\
(0.05)\end{array}$ \\
\hline $\begin{array}{l}\text { Expected Ask } \\
\text { * Avoidable Information }^{*} \text { Male }\end{array}$ & & & & & $\begin{array}{l}-0.06 \\
(0.09)\end{array}$ & $\begin{array}{l}-0.05 \\
(0.09)\end{array}$ \\
\hline Constant & $\begin{array}{c}0.52^{* * *} \\
(0.04)\end{array}$ & $\begin{array}{c}0.43^{* * *} \\
(0.02)\end{array}$ & $\begin{array}{c}0.52^{* * *} \\
(0.04)\end{array}$ & $\begin{array}{c}0.45^{* * *} \\
(0.04)\end{array}$ & $\begin{array}{c}0.52^{* * *} \\
(0.04)\end{array}$ & $\begin{array}{c}0.44^{* * *} \\
(0.01)\end{array}$ \\
\hline Controls & no & yes & no & yes & no & yes \\
\hline Observations & 1989 & 1989 & 3973 & 3973 & 3987 & 3987 \\
\hline Click-through rates & 0.46 & 0.46 & 0.46 & 0.46 & 0.45 & 0.45 \\
\hline
\end{tabular}

${ }^{*} p<0.10,{ }^{* *} p<0.05,{ }^{* * *} p<0.01$. Standard errors are clustered at the voted-for animal group level and shown in parentheses. The results are from a linear probability model of likelihood to click-through to the donation page of voted-for animal group. Expected Ask, Unavoidable Info, Avoidable Info, and Male are indicators for when the ask is expected, the information provided is unavoidable, the information provided is avoidable, and the participant is male. Controls include indicators for each individual's day that they voted during the contest, selected animal groups, and previous supporters. 
Table A.4: By type of supporter, viewing behavior regressions

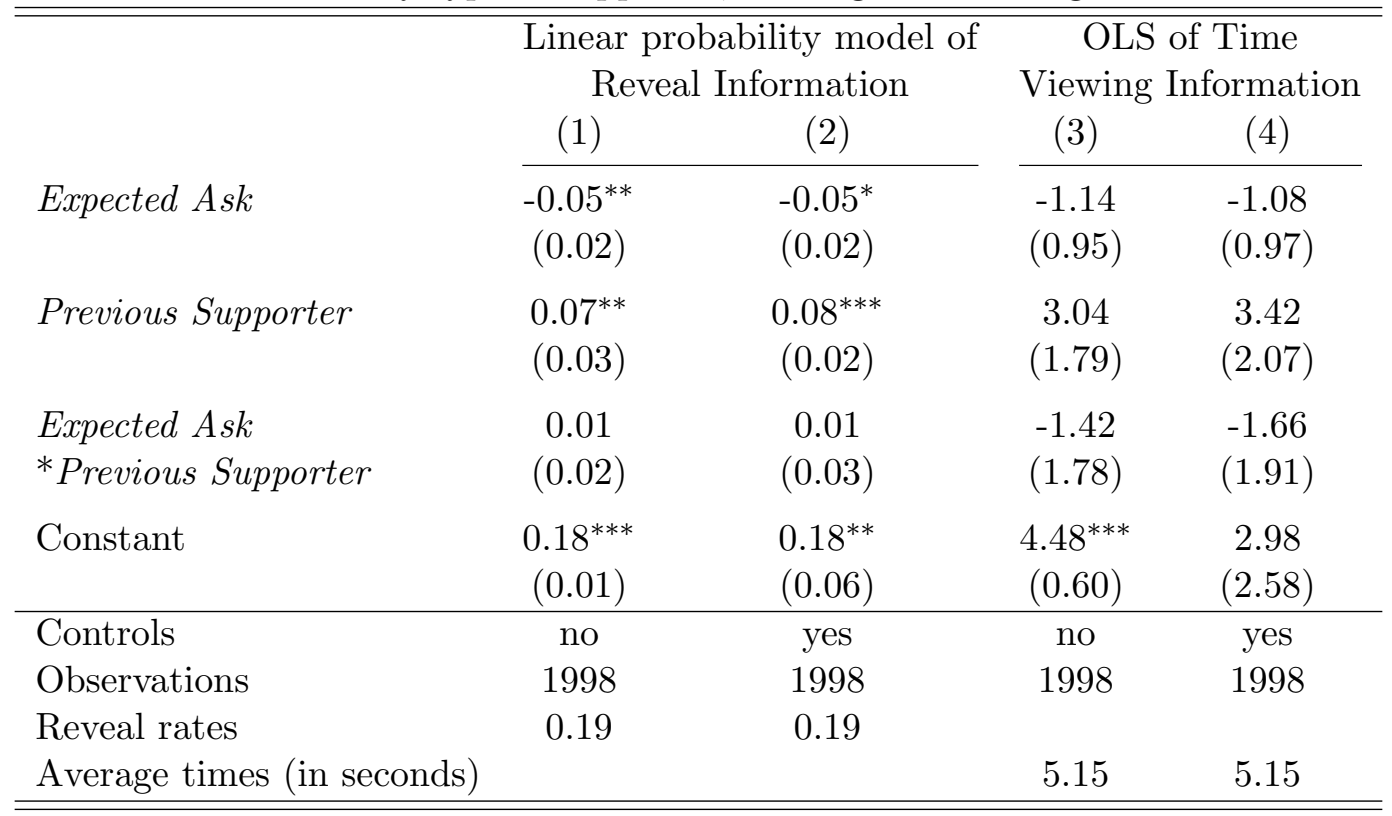

${ }^{*} p<0.10,{ }^{* *} p<0.05,{ }^{* * *} p<0.01$. Standard errors are clustered at the voted-for animal group level and shown in parentheses. The results in the first panel are from a linear probability model of likelihood to reveal the information. The results in the second panel are from OLS regressions of seconds spent viewing the information in the Avoidable Information treatments, which equals 0 if the information is not revealed. If the information is revealed, we define the time spent viewing the information as the amount of seconds that elapses between participants clicking to reveal it and their final click on the page to continue to the next step (or in rare cases, their click to close the story after choosing to reveal it). Expected Ask is an indicator for the Expected Ask treatments. Controls include indicators for each individual's day that they voted during the contest, selected animal groups, and males. Data include the observations from the Avoidable Information treatments. 
Table A.5: By type of supporter, average time individuals spend viewing information when it is avoidable but chosen to be revealed

\begin{tabular}{lcc}
\hline \hline Ask: & Unexpected & Expected \\
\hline New Supporters & & \\
(a) If clicked-through & 28 & 21 \\
(b) If did not click-through & 22 & 32 \\
Observations & 86 & 58 \\
\hline Previous Supporters & & \\
(a) If clicked-through & 36 & 23 \\
(b) If did not click-through & 22 & 24 \\
Observations & 129 & 117 \\
\hline \hline
\end{tabular}

We define the time participants spend viewing the information in the Avoidable Information treatments as the amount of seconds that elapses between participants clicking to reveal it and their final click on the page to continue to the next step (or in rare cases, their click to close the information after choosing to reveal it). Similar findings result if one instead defines the time participants spend viewing the information as the amount of seconds that elapses between their first click on the page (presumably from answering the question about how they know their voted-for animal group) and their final click on that page to continue to the next step.

Table A.6: By type of supporter, average time individuals spend viewing information when it is unavoidable

\begin{tabular}{lcc}
\hline \hline Ask: & Unexpected & Expected \\
\hline New Supporters & & \\
(a) If click-through & 32 & 31 \\
(b) If do not click-through & 30 & 27 \\
Observations & 458 & 455 \\
\hline Previous Supporters & & \\
(a) If click-through & 32 & 29 \\
(b) If do not click-through & 21 & 24 \\
\hline Observations & 522 & 550 \\
\hline \hline
\end{tabular}

We define the time participants spend viewing the information in the Unavoidable Information treatments as the amount of seconds that elapses between their first click on the page (presumably from answering the question about how they know their voted-for animal group) and the final click on that page to continue to the next step. 
Table A.7: Donation regressions from both online studies

\begin{tabular}{|c|c|c|c|c|}
\hline & $\begin{array}{l}\text { Line } \\
\text { in main } \\
(1)\end{array}$ & $\begin{array}{l}\text { orobabilit } \\
\text { ine study } \\
(2)\end{array}$ & $\begin{array}{c}\text { model of } \\
\text { in eithel } \\
(3)\end{array}$ & $\begin{array}{l}\text { nation } \\
\text { line study } \\
\qquad(4)\end{array}$ \\
\hline Expected Ask & $\begin{array}{c}-0.06^{* *} \\
(0.03)\end{array}$ & $\begin{array}{c}-0.06^{* *} \\
(0.03)\end{array}$ & $\begin{array}{c}-0.06^{* *} \\
(0.03)\end{array}$ & $\begin{array}{c}-0.06^{* *} \\
(0.03)\end{array}$ \\
\hline Rephrased Expected Ask & $\begin{array}{c}0.02 \\
(0.03)\end{array}$ & $\begin{array}{c}0.03 \\
(0.03)\end{array}$ & $\begin{array}{c}0.02 \\
(0.03)\end{array}$ & $\begin{array}{c}0.02 \\
(0.03)\end{array}$ \\
\hline Unavoidable Ask & & & $\begin{array}{r}0.28^{* * *} \\
(0.03)\end{array}$ & $\begin{array}{c}0.28^{* * *} \\
(0.03)\end{array}$ \\
\hline $\begin{array}{l}\text { Rephrased Expected Ask } \\
\text { * Unavoidable Ask }\end{array}$ & & & $\begin{array}{c}0.03 \\
(0.04)\end{array}$ & $\begin{array}{c}0.02 \\
(0.04)\end{array}$ \\
\hline Constant & $\begin{array}{c}0.62^{* * *} \\
(0.02)\end{array}$ & $\begin{array}{c}0.50^{* * *} \\
(0.14)\end{array}$ & $\begin{array}{c}0.62^{* * *} \\
(0.02)\end{array}$ & $\begin{array}{c}0.53^{* * *} \\
(0.10)\end{array}$ \\
\hline Controls & no & yes & no & yes \\
\hline Observations & 1500 & 1500 & 2299 & 2299 \\
\hline Donation rates & 0.59 & 0.59 & 0.69 & 0.69 \\
\hline
\end{tabular}

${ }^{*} p<0.10,{ }^{* *} p<0.05,{ }^{* * *} p<0.01$. Standard errors are clustered at the voted-for animal group level and shown in parentheses. The results are from OLS regressions of donations to voted-for charity. Data include results from our main online study in Columns (1) and (2), and from either of our online studies in Columns (3) and (4). Expected Ask is an indicator for when the ask is expected. Rephrased Expected $A s k$ is an indicator for when the ask is expected but the expected ask message is rephrased (see Panel C in Appendix Table B.2). Unavoidable Ask is an indicator for when the ask is unavoidable (see Panel C in Appendix Table B.3). Controls include indicators for each selected animal groups, previous supporters, and males. Controls also include self-reports about whether participants answered questions carefully, answered questions randomly, understood the study, have ever volunteered for a charity, or have ever donated to a charity. 


\section{B Complementary Online Studies}

Figure B.1: First Decision (Study 1 and Study 2)

You may choose to vote for one of the charities below. The charity that receives the largest number of votes in this study will receive $\$ 100$ as a donation! Additionally, one participant from this study will be randomly drawn, and the charity chosen by that participant will receive $\$ 25$ as a donation!

Note: Your vote will only count if you complete the entire study.

Which charity would you like to vote for?

ALSAC - St. Jude Children's Research Hospital
American Cancer Society
City of Hope
Oxfam America
Smithsonian Institution
The Nature Conservancy
World Vision


Figure B.2: Text that is displayed between the First and Second Decisions (a) Unexpected Ask treatment (Study 1 and Study 2)

Thank you for voting for American Cancer Society!

On the next page, complete your second decision in this study.

(b) Expected Ask treatment (Study 1)

Thank you for voting for American Cancer Society!

On the next page, complete your second decision in this study, and if you would like to, donate to American Cancer Society.

(c) Rephrased Expected Ask treatment (Study 1 and Study 2)

Thank you for voting for American Cancer Society!

On the next page, complete your second decision in this study about whether you would like to donate to American Cancer Society. 
Figure B.3: Second Decision

(a) Study 1 ("Donation Opportunity Ask")

You have the opportunity to receive up to an additional 100 cents in bonus payment. Any bonus payment you receive will be distributed within one week and is in addition to the $\$ 1$ minimum payment you will receive within 24 hours for completing this study.

On the next page, would you like to show your support for American Cancer Society by having the opportunity to donate some of your bonus payment to them? We hope so!

Yes, I would love to have the opportunity to donate some of my bonus payment.

No, I'd rather not.

(b) Study 1 ("Donation Ask" if answered yes to "Donation Opportunity Ask")

Thank you for choosing to have the opportunity to donate some of your bonus payment to American Cancer Society.

Below, please indicate how much of the additional 100 cents you would like to keep for yourself as a bonus payment and how much of the additional 100 cents you would instead like to donate to American Cancer Society.

Out of 100 cents, how many cents would you like to keep for yourself?

0

Out of 100 cents, how many cents would you like to donate to American Cancer Society?

Total

\section{(c) Study 2 ("Donation Ask")}

You have the opportunity to receive up to an additional 100 cents in bonus payment. Any bonus payment you receive will be distributed within one week and is in addition to the 100 cents you will receive within 24 hours for completing this study.

Below, please indicate how much of the additional 100 cents you would like to keep for yourself as a bonus payment and how much of the additional 100 cents you would instead like to donate to Smithsonian Institution.

Out of 100 cents, how many cents would you like to keep for yourself?

Out of 100 cents, how many cents would you like to donate to Smithsonian Institution? 


\section{Survey Design and Results}

On July 10 2017, we recruited 892 Mturk workers to take part in a survey. Respondents were randomly assigned to one of nine conditions.

Six of the conditions involve respondents evaluating one the treatments from our Field study: the No Information - Unexpected Ask treatment, the No Information - Expected Ask treatment, the Unavoidable Information - Unexpected Ask treatment, the Unavoidable Information - Expected Ask treatment, the Avoidable Information - Unexpected Ask treatment, or the Avoidable Information - Expected Ask treatment. First, respondents were informed that this survey would ask them to view information and then answer questions about an online voting contest that has already occurred. Second, the respondents viewed all of the information provided in the voting contest that preceded Step 3 (i.e., where individuals were asked whether they would like to click-through to the donation page). Third, the respondents were asked the following question:

"On the next page of the voting contest, what do you think individuals viewed?

If you guess correctly, you will receive a bonus payment of 50 cents."

from which they could select one of the following choices:

1. "A thank you note for voting and an invitation to donate to their voted-for charity,"

2. "A thank you note for voting and information on how many votes have been cast for each charity," or

3. "A thank you note for voting and a request to choose from a list the top reasons that influenced their voting."

The percent of respondents "stating that they expect the ask" (i.e., chose 1) is as follows: (i) $77 \%$ in the No Information - Expected Ask treatment versus $64 \%$ in the No Information - Unexpected Ask treatment (two-sided t-test, $p=0.05$ ); (ii) $80 \%$ in the Unavoidable Information - Expected Ask treatment versus 76\% in the Unavoidable Information - Unexpected Ask treatment (two-sided t-test, $p=0.52$ ); and (iii) $65 \%$ in the Avoidable Information - Expected Ask treatment versus $66 \%$ in the Avoidable Information - Unexpected Ask treatment (two-sided t-test, $p=0.73) .{ }^{38}$

\footnotetext{
${ }^{38}$ To try to ensure survey respondents evaluating the Avoidable Information treatment examined the information in a similar manner as participants in our field study, these survey respondents knew that participants in our field study could click to reveal the information (i.e,. the adoption story) but could not click to reveal themselves. Interpreting the survey results among respondents evaluating the Avoidable Information treatments is therefore more difficult.
} 
The three remaining conditions involve respondents evaluating one the treatments from our complementary online studies: the Unexpected Ask treatment, the Expected Ask 1 treatment, and the Expected Ask 2 treatment. The procedure for these respondents is the same as for those who are assigned to evaluate one of the treatments from our Field study except these respondents were informed that they would view information and then answer questions about a previous Mturk study (instead of an online voting contest).

The percent of respondents "stating that they expect the ask" (i.e., chose 1) is as follows: $33 \%$ in the Unexpected Ask treatment, 78\% in the Expected Ask 1 treatment, and 69\% in the Expected Ask 2 treatment. While the difference between the Expected Ask 1 and Expected Ask 2 treatments is not statistically significant, respondents are significantly more likely to state they expect the ask in the Expected Ask treatments than in the Unexpected Ask treatment (two-sided t-test, $p<0.01$ ). 